\title{
Modified screen-printed electrode for the FIA-amperometric determination of 2-nitro-p-phenylenediamine
}

\author{
Bryan C. Huayhuas-Chipana ${ }^{\mathrm{a}}$, Marcos Vinicius Foguel ${ }^{\mathrm{a}}$, Luís Moreira Gonçalves ${ }^{\mathrm{b}}$, Maria D.P.T. Sotomayor ${ }^{\mathrm{a}, *}$ \\ a Instituto de Química, UNESP-Univ Estadual Paulista, Departamento de Química Analítica, Araraquara, SP, Brazil \\ ${ }^{\mathrm{b}}$ REQUIMTE/LAQV, Departamento de Química e Bioquímica, Faculdade de Ciências, Universidade do Porto (FCUP), Porto, Portugal
}

\section{A R T I C L E I N F O}

\section{Article history:}

Received 18 October 2016

Received in revised form 27 November 2016

Accepted 29 November 2016

Available online 1 December 2016

\section{Keywords:}

2-Nitro-p-phenylenediamine

Flow analysis

Electroanalysis

Electrochemical sensor

Electrochemistry

Microfluidics

\begin{abstract}
A B S T R A C T
This work presents the development of a modified sensor coupled to a flow injection analysis (FIA) system for the determination of 2-nitro-p-phenylenediamine, an important compound in hair dyes. To achieve this, a commercial screen-printed gold electrode (SPAuE) previously electrochemically treated to become nanostructured, was covered with a self-assembled monolayer (SAM) of 3-mercapto-1-propanesulfonate (MPS) and, subsequently, was covered by multilayers of chitosan, sodium dodecyl sulphonate (SDS) and nickel(II) phthalocyaninetetrasulfonic acid (NiPcTs) in a layer-by-layer technique to improve the sensor's sensibility. The analytical response of the proposed methodology was evaluated in batch by square wave voltammetry (SWV) and by amperometry coupled to a FIA system, with limits of detection of 1.2 and $1.6 \mu \mathrm{mol} \mathrm{L}{ }^{-1}$, respectively.
\end{abstract}

(c) 2016 Elsevier B.V. All rights reserved.

\section{Introduction}

The use of hair dyes is generally regarded as safe, however, a few studies can be found literature alarming us for their potential toxicity, due to its mutagenic properties, as well as allergenic potential [1-6]. Therefore, the existence of analytical methodologies capable of determining these compounds in waste waters can be of great interest for researchers. One of the main compounds used in commercial formulations is 2-nitro-pphenylenediamine (2NPPD), about which some concerning studies about its toxicity and mutagenicity have been performed $[7,8]$.

A large number of techniques and approaches can be found in literature to improve the sensitivity of bare electrodes. They range from actually altering the electrode structure, to add some extra layers of materials like polymers, up to incorporate bioactive elements. Creating electrochemical sensors is a field of science where the scientist's imagination is fully tested. Self-assembled monolayers (SAM) have been a popular option, SAMs are single molecule layers that spontaneously adsorb onto a chosen surface, usually containing a thiol group, they are quite advantageous since they allow the binding of other important elements from enzymes to DNA onto the electrode surface, quite commonly made out of gold [9-12].

Commercial electrochemical flow-through detectors have become widely available, including for low volumes. Therefore combining flow-injection analysis (FIA) with electrochemical sensors is an option that allows automation, low sample and reagents requirements, suitable repeatability along with low-cost portability [13-15].

\footnotetext{
* Corresponding author.

E-mail address: mpilar@iq.unesp.br (M.D.P.T. Sotomayor).
}

The present work explores a method to build sensor that could have sufficient sensitivity for the detection of 2NPPD. The sensor was constructed using a purposely build nanostructured gold surface on a commercial screen printed electrode modified with a self-assembled monolayer (SAM) of 3-mercapto-1-propanesulfonate (MPS) and, subsequently, was covered by multilayers of chitosan, sodium dodecyl sulphonate (SDS) and nickel(II) phthalocyanine-tetrasulfonic acid (NiPcTs).

\section{Experimental}

\subsection{Reagents}

All chemicals were of analytical grade and were used as received without further purification. Sodium 3-mercapto-1-propanesulfonate (MPS), 2NPPD, chitosan, nickel(II) phthalocyanine-tetrasulfonic acid tetrasodium salt (NiTSPc), sodium dodecyl sulphonate (SDS) were purchased from Sigma-Aldrich. In the electrochemical measurements a Britton-Robinson buffer (BRB), $0.1 \mathrm{~mol} \mathrm{~L}^{-1}$, was used. It was prepared with boric acid, acetic acid and phosphoric acid. Ultrapure water (resistivity not lower than $18.2 \mathrm{M} \Omega \mathrm{cm}$ at $298 \mathrm{~K}$ ) from a Direct-Q 3UV water purification system (Millipore) was used in all experiments.

\subsection{Apparatus}

Batch electrochemical measurements were performed in a digital potentiostat/galvanostat Autolab PGSTAT 12 controlled with software GPES v.4.9. A single-compartment electrochemical cell with a volume 
of $10 \mathrm{~mL}$ was employed. Screen printed gold electrodes (SPAuEs) with a gold working electrode (diameter of $4 \mathrm{~mm}$, geometric area of $0.125 \mathrm{~cm}^{2}$ ), a pseudo silver reference and gold counter-electrode were acquired from DropSens. Electrochemical measurements in FIA were performed with a PalmSens3 potentiostat from Palm Sense using an acrylic cell type thin layer flow with magnet system to close it from DropSens (DRP-FLWCL) and a multi-channel peristaltic pump from Ismatec. All measurements were performed at room temperature.

All SPAuEs were electrochemically cleaned by performing cyclic voltammetry in a sodium hydroxide solution, $0.5 \mathrm{~mol} \mathrm{~L}^{-1}$, and then immersed in ethanol.

The morphology of the electrode surface was characterized by a high-resolution field emission scanning electron microscopy (FESEM) a using a JEOL JSM 7500F, no sample preparation was performed. Topographical images were obtained using an atomic force microscope (AFM) Agilent 5500, acoustic AC mode, spring constants of $42 \mathrm{~N} \mathrm{~m}^{-1}$ and resonant frequency of $320 \mathrm{kHz}$.

\section{Results and discussion}

\subsection{Electrode manufacturing and its characterization}

As schematized in Fig. 1 building the electrochemical sensor had several steps. It started with creating nanopores on the gold surface, placing a SAM and then several layers of chitosan-SDS-chitosan-NiPcTs. This will be discussed in detail in the next paragraphs.

Initially, the working electrode of gold was cleaned using cyclic voltammetry in a $0.5 \mathrm{~mol} \mathrm{~L}^{-1}$ sulphuric acid solution in a potential range from -0.2 to $+1.0 \mathrm{~V}$ at a scan rate of $50 \mathrm{mV} \mathrm{s}^{-1}$. In order to form the gold nanostructure, the first step was a galvanostatic pre-treatment, i.e. submitting the electrode to a cathodic potential of $+2.0 \mathrm{~V}$ for $180 \mathrm{~s}$ in a phosphate buffer solution, $\mathrm{pH}$ 7.0, to obtain an oxide film of gold. Then, cathodic linear sweep voltammetry was performed in the same solution using a potential range from +2.0 to $-0.2 \mathrm{~V}$, for the reduction of the gold oxide, previously formed, and thus obtaining the roughened surface [16]. At a potential of $+2.0 \mathrm{~V}$ at a $\mathrm{pH} 7$, according to the gold Pourbaix diagram [16], there is an equilibrium between $\mathrm{Au}(\mathrm{OH})_{3}$ and $\mathrm{AuO}_{2}$, and quite possibly it is the release of oxygen bubbles when passing from $\mathrm{AuO}_{2}$ to $\mathrm{Au}(\mathrm{OH})_{3}$ that creates the nanopores.

Fig. 2(A) shows the cyclic voltammetry of the nanostructured gold electrode and the electrode without this pre-treatment. There is a significant improvement in current intensity after the mentioned treatment on the gold surface due to increased surface area of the electrode. The active areas of untreated and nanostructured electrodes were estimated using the corresponding cathodic peak areas. These areas correspond to the removal of a monolayer of oxygen on the gold electrode surface, enabling the active area to be calculated using Eq. (1):

$Q=\frac{1}{v} \int_{E i}^{E f} I d E-Q_{d c}$

where $Q$ is the total electrical charge; $Q_{d c}$ is the electrical charge of the capacitive double layer; $v$ is a constant specific to gold (390 $\mathrm{mC} \mathrm{cm}^{-2}$ ), and the remaining integral corresponds to the active area of the electrode. The active areas of the two electrodes were calculated to be $0.137 \mathrm{~cm}^{2}$ to the bare gold and $2.46 \mathrm{~cm}^{2}$ to the nanostructured gold [16]. This means the area of the nanostructured electrode is 18 times larger than the bare electrode. The highly roughness surface is also visible by both SEM and AFM (Fig. 3). This increase in the available area for adsorption is expected to greatly increase the sensor's electrochemical signal.

Then, after altering the gold surface, the first step in the development of sensor was the immersion of the gold electrode for $3 \mathrm{~h}$ at room temperature in $10 \mathrm{~mL}$ of $20 \mathrm{mmol} \mathrm{L}^{-1}$ MPS solution prepared in $10 \mathrm{mmol} \mathrm{L}^{-1}$ sulphuric acid solution for the formation of the SAM. After the incubation time, the electrode was washed with water. Gold is very advantageous since it does not react with the oxygen present in the environment [17].

Afterwards, the formation of multilayers using the layer-by-layer technique on the SAM was carried out using different modifiers based on the surface charge of modified gold with SAM. To achieve this, the modified electrode with MPS was immersed in a cationic solution of $1 \mathrm{~g} \mathrm{~L}^{-1}$ chitosan at $\mathrm{pH} 3.8$ for $10 \mathrm{~min}$ and rinsed with water for $3 \mathrm{~min}$. Immediately thereafter, it was immersed in $1 \%$ SDS solution for $10 \mathrm{~min}$ and rinsed with water. Afterwards, the electrode was again immersed in a cationic solution of $1 \mathrm{~g} \mathrm{~L}^{-1}$ chitosan and rinsed. Finally, it was immersed in an anionic solution of $0.1 \mathrm{mmol} \mathrm{L}^{-1}$ NiTSPc for $10 \mathrm{~min}$. Metallic phthalocyanines are suitable to replace enzymes in sensor applications since they can mimic natural enzymes, making the electron transfer easier $[18,19]$. This procedure (from chitosan-SDS) was repeated several times to reach surfaces that could provide higher currents. The interaction between chitosan and SDS creates a very stable

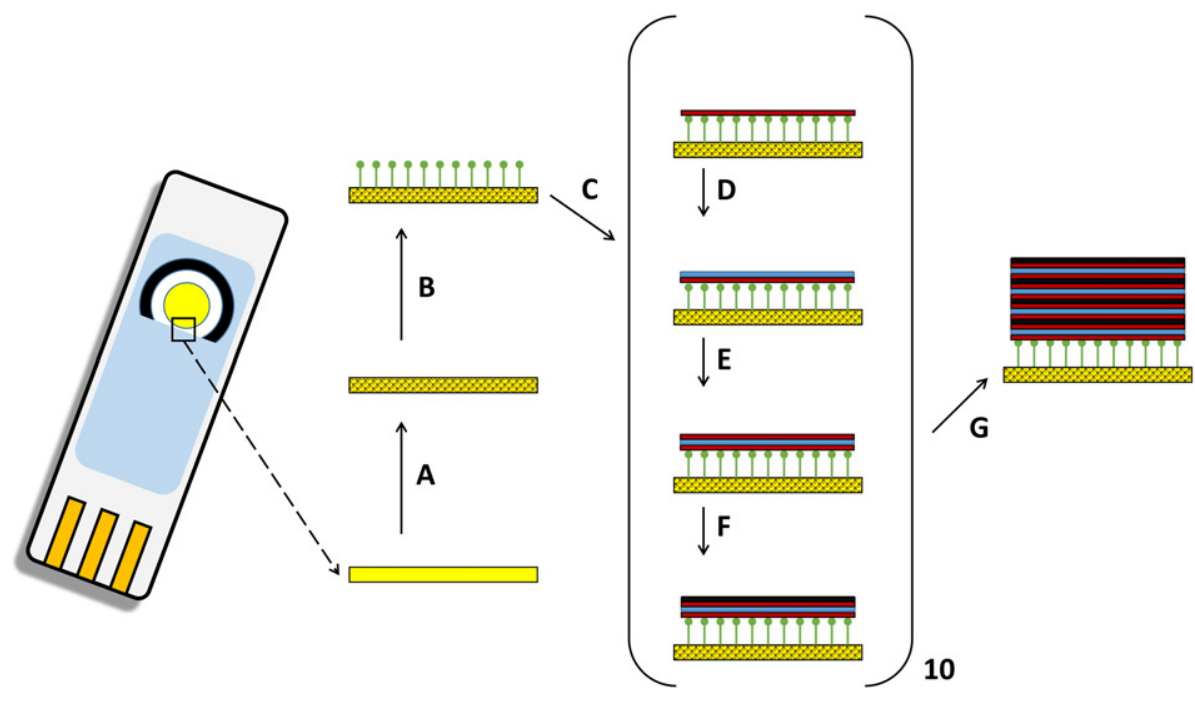

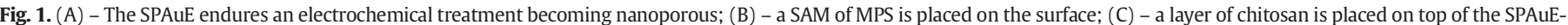

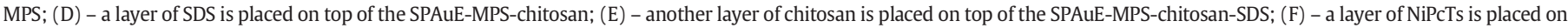

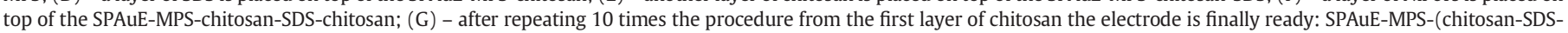
chitosan-NiPcTs) 10 . 

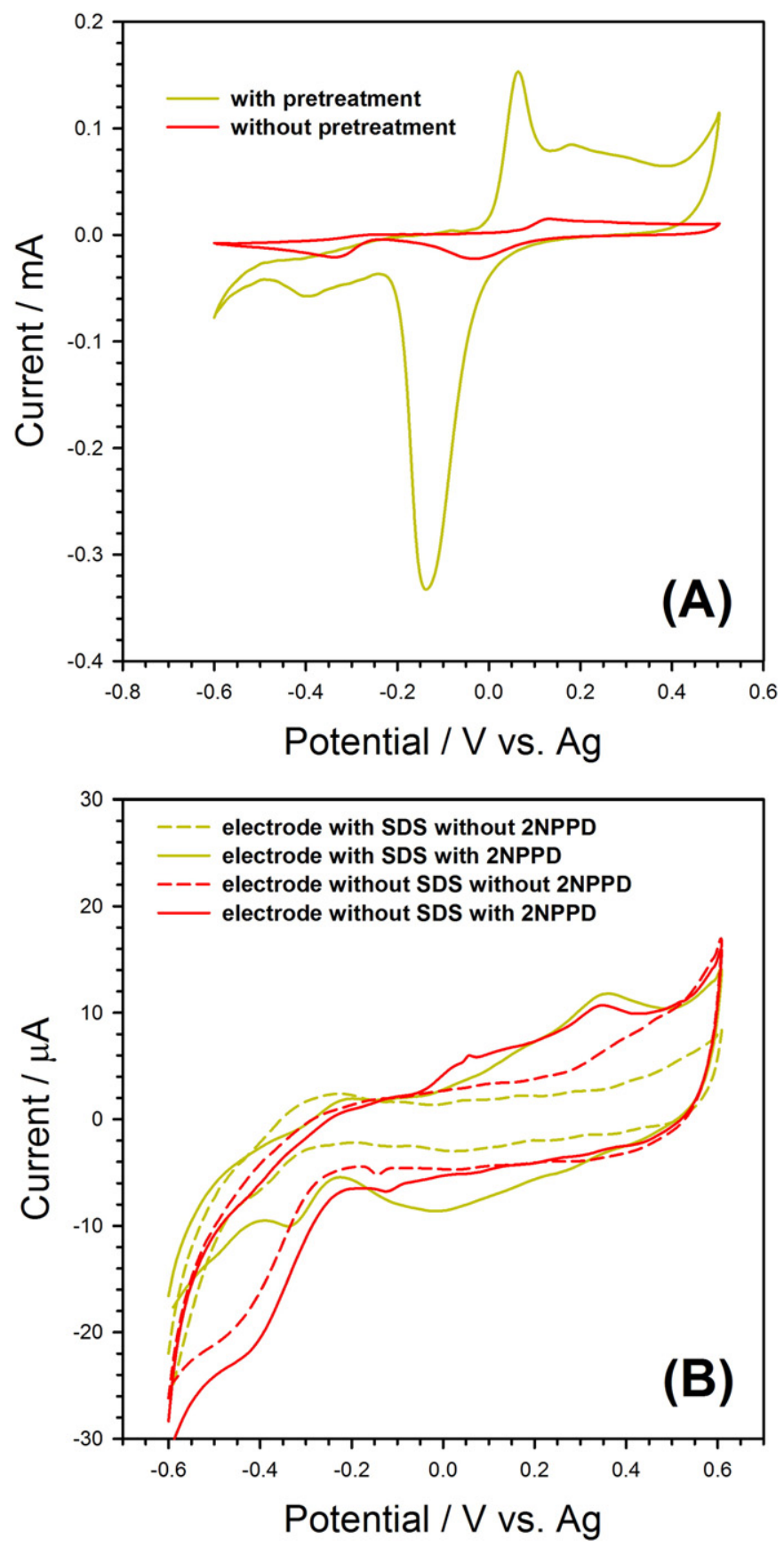

Fig. 2. (A) Cyclic voltammograms in $0.5 \mathrm{~mol} \mathrm{~L}^{-1}$ of potassium hydroxide solution at a scan rate of $50 \mathrm{mV} \mathrm{s}^{-1}$ of the screen-printed gold electrodes before and after the treatment for nanostructured gold formation; (B) cyclic voltammograms in BRB, $0.1 \mathrm{~mol} \mathrm{~L}^{-1}, \mathrm{pH} 3.5$, at a scan rate $50 \mathrm{mV} \mathrm{s}^{-1}$, with a modified electrode with and without SDS and in the presence and without presence of 2NPPD, $225 \mu \mathrm{mol} \mathrm{L}{ }^{-1}$.

film ideal for this work's objective, moreover the cationic nature of chitosan easily adsorbs on the anodic surface of the SAM formed [20]. Layer-by-layer technique is a very simple and useful technique, it is performed without any particular requirements like temperature changes or by creating vacuum and it can be used with a large variety of polyelectrolytes [21,22]. As it can be observed in Fig. 4 the current increases with the number of layers in sensor SPAuE-MPS-(chitosan-SDS-chitosan-NiPcTs) $n$. Thus, to increase the signal a larger number of layers could be used. A compromise of 10 layers was chosen not to burden the scientist with too much manual work. Chitosan in this sensor plays a role of support (SDS and NiPcTs), chitosan's stability in terms of temperature, $\mathrm{pH}$ and storage are appreciated when building sensors [23-25]. As shown in Fig. 2(B) the anionic surfactant SDS improves the sensor's signal difference between the presence and absence of the analyte, SDS is positively charged with a apolar tail helping to 'bind' the different layers in a more consistent manner for the different elements [26].

\subsection{Analytical application of the developed sensor}

For analytical purposes square-wave voltammetry was applied. Differential pulse techniques are employed due to their high sensitivity, good definition of signals and reduction of double layer and background currents [27]. Therefore it is not surprising that SWV is used extensively for electroanalytical purposes [28-30]. Optimized SWV parameters were the following: square wave frequency of $80 \mathrm{~Hz}$ and wave amplitude of $70 \mathrm{mV}$.

With the goal of evaluating selectivity, the sensor's response for several different compounds (metronidazole, histidine, ciprofloxacin, diclofenac, glutathione, catechin and biotine) was compared to 2NPPD (Fig. 5). Measurements were performed in the same experimental conditions, namely: room temperature, concentration $\left(4.45 \mu \mathrm{mol} \mathrm{L}^{-1}\right)$ and $\mathrm{pH}$ 3.5. It can be observed than no signal different from blank was obtained for metronidazole, histidine, ciprofloxacin and diclofenac, however for catechin, biotine and glutathione signals ca. $35 \%$ of 2 NPPD were observed. Although diclofenac, ciprofloxacin and metronidazole do not possess any aliphatic amine group, histidine has indeed one group. Biotine's and glutathione's signal should be ascribed to its sulphur oxidation and catechin's signal to its hydroxyl groups.

The "batch" method performance parameters were obtained from a calibration curve (Fig. $6(\mathrm{~A}))$ and are the following: $\Delta I(\mu \mathrm{A})=(0.62 \pm$ $0.02) \times[2 \mathrm{NPPD}]\left(\mu \mathrm{mol} \mathrm{L}{ }^{-1}\right)+(1.8 \pm 0.3), r^{2}$ of 0.998 , limit of detection (LOD) of $1.2 \mu \mathrm{mol} \mathrm{L}^{-1}$ and limit of quantification (LOQ) of $4.1 \mu \mathrm{mol} \mathrm{L}^{-1}$. LOD and LOQ were calculated as three and ten times the standard deviation of the intercept/slope, respectively. The linear dynamic range was from 4.3 up to $22.5 \mu \mathrm{mol} \mathrm{L}{ }^{-1}$.

Since the sensor worked well in batch, aiming to automatize the methodology, use small sample volumes and miniaturize the SPAuEMPS-(chitosan-SDS-chitosan-NiPcTs) 10 sensor was tried in a FIA system. Volumes of $50 \mu \mathrm{L}$ were analyzed with a flow of $1.12 \mathrm{~mL} \mathrm{~min}^{-1}$, measurements were performed in this case by amperometry at a potential of $+400 \mathrm{mV}$, at a $\mathrm{pH}$ of 3.5 .

The "FIA" method performance parameters were obtained from a calibration curve (Fig. $6(\mathrm{~B}))$ and are the following: $\Delta I(\mu \mathrm{A})=$ $(0.031 \pm 0.001) \times[2 \mathrm{NPPD}]\left(\mu \mathrm{mol} \mathrm{L}{ }^{-1}\right)+(0.03 \pm 0.02), r^{2}$ of 0.996 , LOD of $1.6 \mu \mathrm{mol} \mathrm{L}-1$ and LOQ of $5.4 \mu \mathrm{mol} \mathrm{L}{ }^{-1}$. LOD and LOQ were calculated as three and ten times the standard deviation of the intercept/ slope, respectively. The linear dynamic range was from 5.4 up to $22.5 \mu \mathrm{mol} \mathrm{L}{ }^{-1}$. A sampling rate of 36 injections per hour was obtained. Repeatability was tested measuring several different injections of 2NPPD, $9.0 \mu \mathrm{mol} \mathrm{L}^{-1}$, in the FIA system, and the relative standard deviation (RSD) obtained was $1.4 \%(n=20)$. The sensor produced reproducible results during five days (data not shown). Recovery studies were performed over five tap water samples spiked with $15 \mu \mathrm{mol} \mathrm{L}{ }^{-1}$ 2NPPD solution ( $50 \mu \mathrm{L}$ of these samples were added to $10 \mathrm{~mL}$ of BRB solution at $\mathrm{pH}$ 3.5), and, as can be seen in Table 1, results were very good being the recovery ca. $100 \%$.

A few analytical methodologies for 2NPPD can be found in literature, namely by GC-MS [31], HPLC with several different types of detectors $[32,33]$, with a fluorometric sensor [34], with a glassy carbon electrode coated by composites of multiwall carbon nanotubes with chitosan (GCE-MWCNTs-chitosan) [35]. The developed sensor, both in batch and in the FIA system, has a lower LOD when compared to the other sensors in literature ( $30 \mu \mathrm{mol} \mathrm{L}^{-1}$ [34] and $7.3 \mu \mathrm{mol} \mathrm{L}{ }^{-1}$ [35]) and it is only beaten by the chromatographic methodologies $\left(0.9 \mu \mathrm{mol} \mathrm{L}^{-1}\right.$ [31] and $0.2 \mu \mathrm{mol} \mathrm{L}-1$ [32]). 

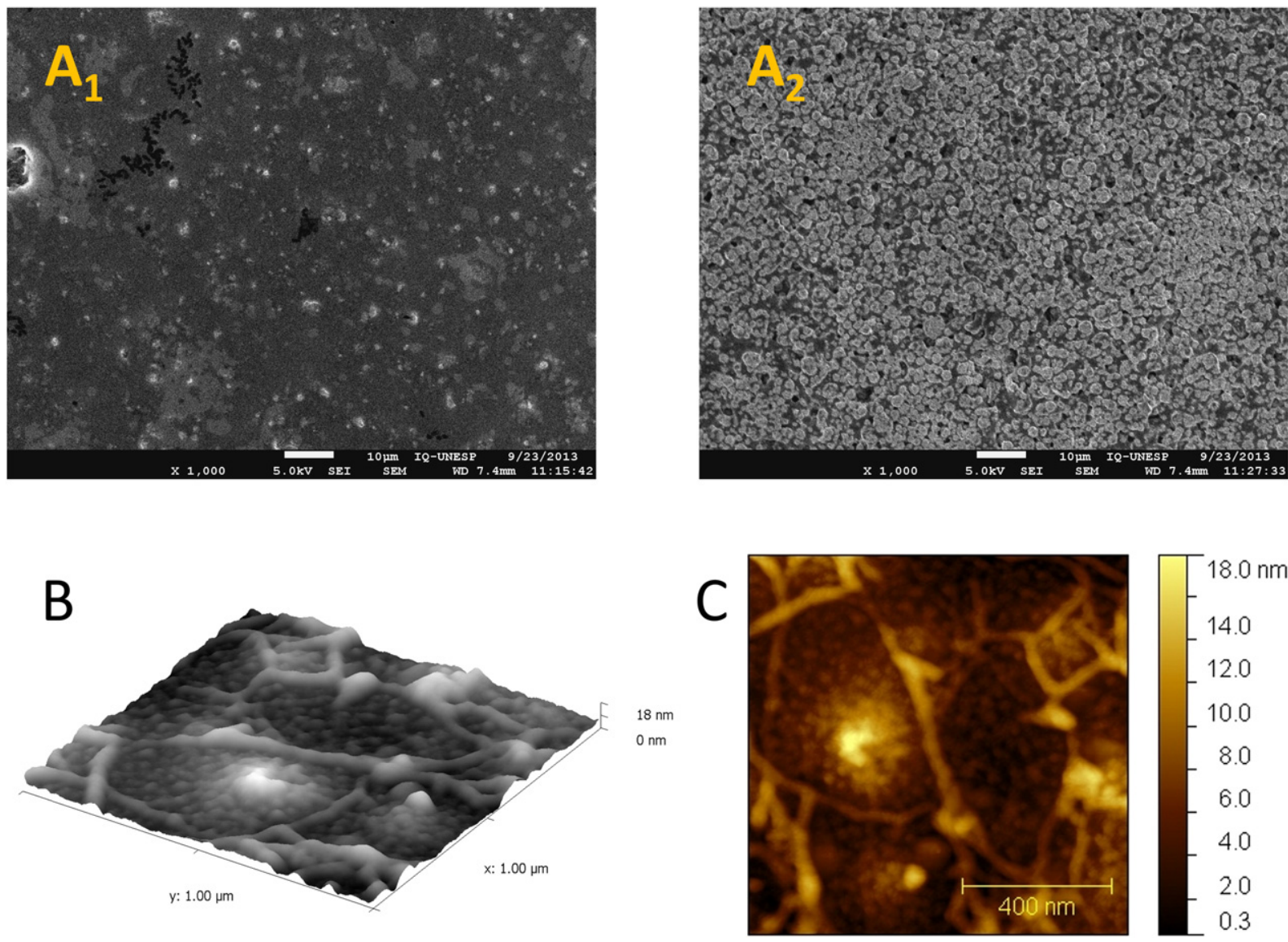

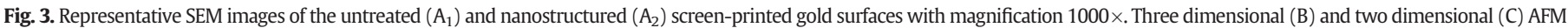
images of the nanostructured screen-printed gold electrodes.

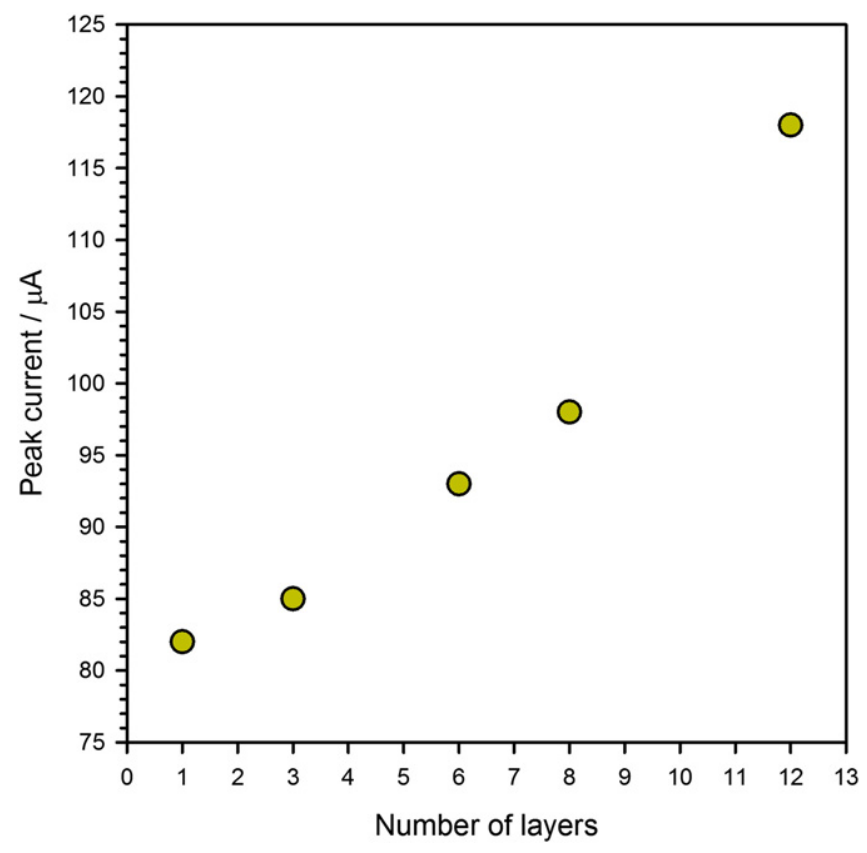

Fig. 4. Change in the anodic peak current with the sensor's number of layers, experiments were performed in BRB, $0.1 \mathrm{~mol} \mathrm{~L}^{-1}, \mathrm{pH} 3.5$, with 2NPPD concentration $18 \mu \mathrm{mol} \mathrm{L}^{-1}$ at a scan rate $50 \mathrm{mV} \mathrm{s}^{-1}$.

\section{Conclusions}

A SPAuE-MPS-(chitosan-SDS-chitosan-NiPcTs) 10 sensor was developed to analyse 2NPPD. Firstly the commercial gold electrode was electrochemically treated to obtain a nanostructured surface. Then, on top a MPS SAM, 10 layers of chitosan-SDS-chitosan-NiPcTs were placed by the layer-by-layer technique. On batch, by SWV a LOD of $1.2 \mu \mathrm{mol} \mathrm{L} \mathrm{L}^{-1}$

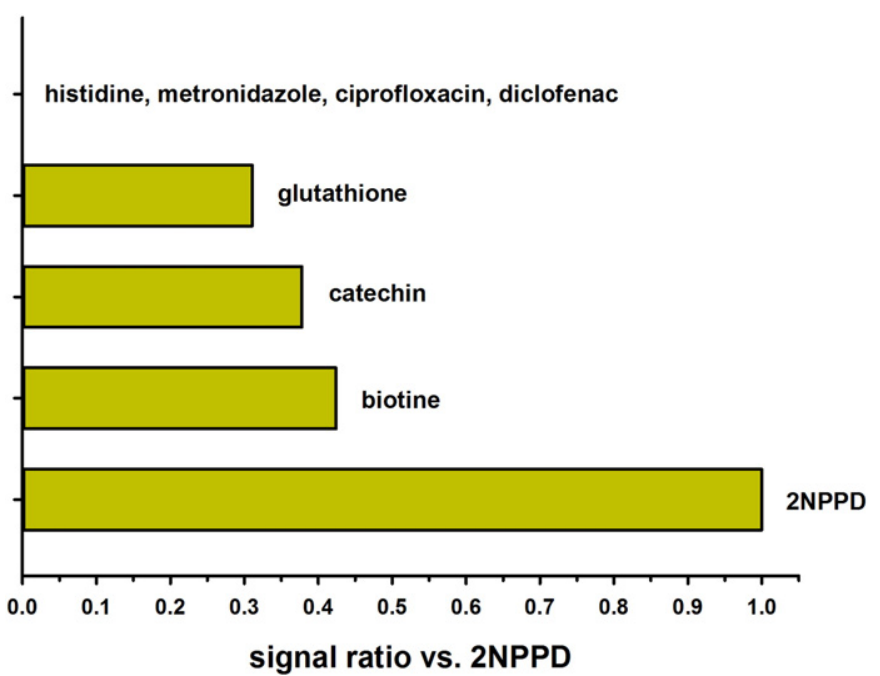

Fig. 5. Selectivity studies, sensor's response when compared to 2NPPD for different compounds (metronidazole, histidine, ciprofloxacin, diclofenac, glutathione, catechin and biotine). Experiments were performed in $\mathrm{BRB}, 0.1 \mathrm{~mol} \mathrm{~L}^{-1}, \mathrm{pH} 3.5$, all concentrations being $4.45 \mu \mathrm{mol} \mathrm{L}^{-1}$ at a scan rate $50 \mathrm{mV} \mathrm{s}^{-1}$. 

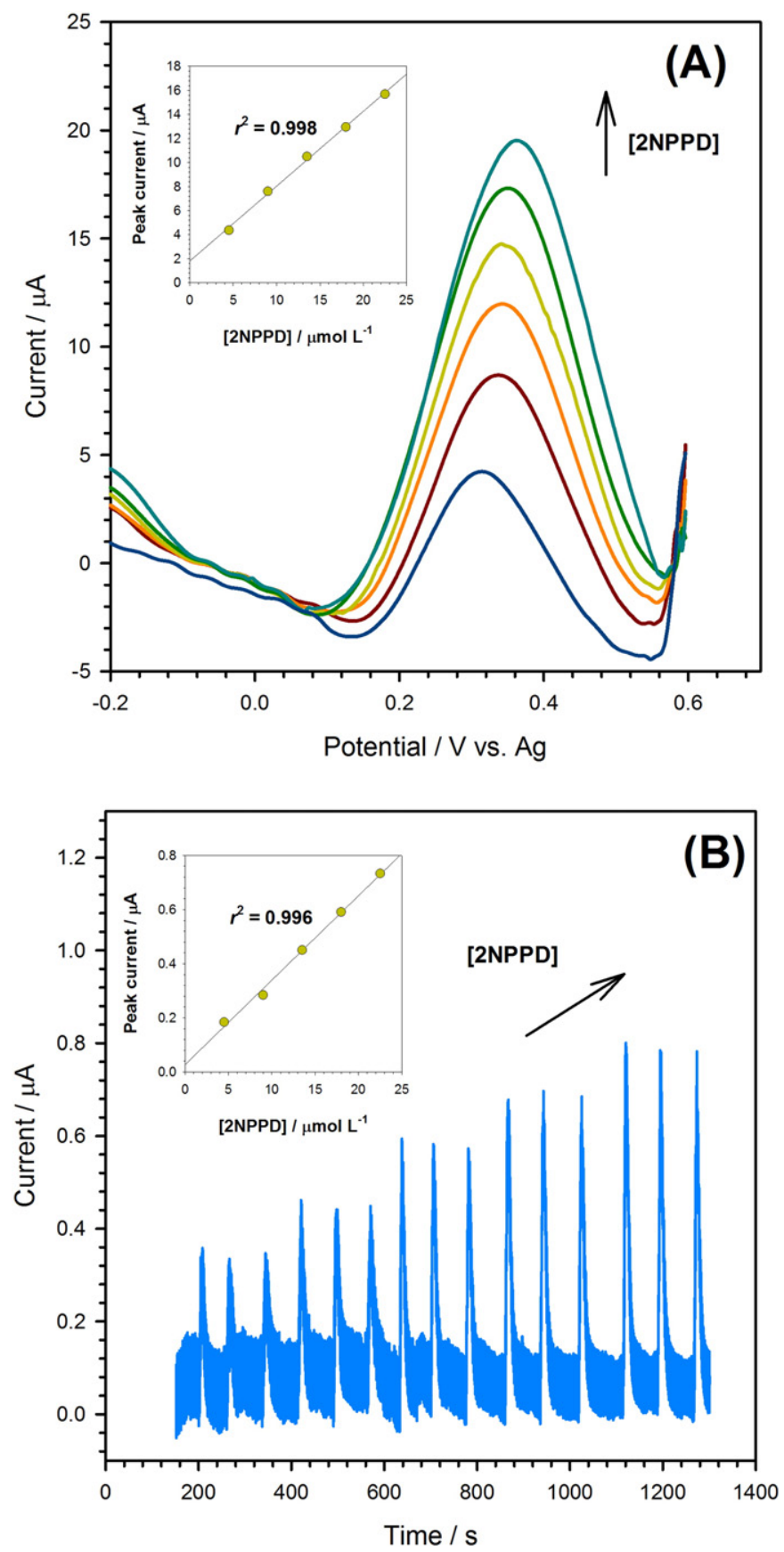

Fig. 6. (A) Square wave voltammograms of 2NPPD using SPAuE-MPS-(chitosan-SDSchitosan-NiPcTs) ${ }_{10}$ (concentrations from 4.5 to $22.5 \mu \mathrm{mol} \mathrm{L}{ }^{-1}$ ), $\mathrm{pH} 3.5$, frequency $80 \mathrm{~Hz}$ and an wave amplitude of $70 \mathrm{mV}$. Inlay: calibration curve obtained. (B) Amperometry by SPAuE-MPS-(chitosan-SDS-chitosan-NiPcTs) ${ }_{10}$ in FIA (concentrations from 4.5 to $22.5 \mu \mathrm{mol} \mathrm{L}{ }^{-1}$ ), measurements were performed at a potential of $+400 \mathrm{mV}, \mathrm{pH}$ of 3.5 at a flow rate of $1.12 \mathrm{~mL} \mathrm{~min}^{-1}$. Inlay: calibration curve obtained.

was obtained, then in FIA system a LOD of $1.6 \mu \mathrm{mol} \mathrm{L}{ }^{-1}$ was obtained with a sampling rate of $36 \mathrm{~h}^{-1}$, recoveries around $100 \%$ and a RSD of $1.4 \%$.

Table 1

Recovery studies in tap water spiked with 2NPPD in a concentration of $15 \mu \mathrm{mol} \mathrm{L}{ }^{-1}$, each sample was analyzed in triplicate.

\begin{tabular}{|c|c|c|c|c|c|}
\hline Sample & 1 & 2 & 3 & 4 & 5 \\
\hline $2 \mathrm{NPPD} / \mu \mathrm{mol} \mathrm{L}{ }^{-1}$ & $15.3 \pm 0.6$ & $15.0 \pm 0.3$ & $14.5 \pm 0.1$ & $15.1 \pm 0.1$ & $14.7 \pm 0.7$ \\
\hline Recovery/\% & 102.0 & 100.1 & 96.9 & 100.5 & 97.7 \\
\hline
\end{tabular}

\section{Acknowledgements}

The authors would like to express their sincerest gratitude and indebtedness to the Research Funding Agencies CNPq (400459/2012-4 and 303690/2012-7) and FAPESP (2016/06926-0). LMG (SFRH/BPD/ 76544/2011) wishes to acknowledge FCT for their PhD studentship and post-doctoral grant. BCHC is grateful to CAPES for his scholarship.

\section{References}

[1] B.N. Ames, H.O. Kammen, E. Yamasaki, Hair dyes are mutagenic: identification of a variety of mutagenic ingredients, Proc. Natl. Acad. Sci. U. S. A. 72 (1975) 2423-2427.

[2] S.Y. Tai, H.M. Hsieh, S.P. Huang, M.T. Wu, Hair dye use, regular exercise, and the risk nd prognosis of prostate cancer: multicenter case-control and case-only studies, BMC Cancer 16 (2016).

[3] M.M. Ros, M. Gago-Dominguez, K.K.H. Aben, H.B. Bueno-De-Mesquita, E. Kampman, S.H. Vermeulen, L.A. Kiemeney, Personal hair dye use and the risk of bladder cancer: a case-control study from the Netherlands, Cancer Causes Control 23 (2012) 1139-1148.

[4] H.M. Bolt, K. Golka, The debate on carcinogenicity of permanent hair dyes: new insights, Crit. Rev. Toxicol. 37 (2007) 521-536.

[5] K.H. Kim, E. Kabir, S.A. Jahan, The use of personal hair dye and its implications for human health, Environ. Int. 89-90 (2016) 222-227.

[6] B. Takkouche, M. Etminan, A. Montes-Martínez, Personal use of hair dyes and risk of cancer: a meta-analysis, J. Am. Med. Assoc. 293 (2005) 2516-2525.

[7] K.T. Chung, C.A. Murdock, S.E. Stevens Jr., Y.S. Li, C.I. Wei, T.S. Huang, M.W. Chou, Mutagenicity and toxicity studies of $p$-phenylenediamine and its derivatives, Toxicol. Lett. 81 (1995) 23-32.

[8] S.M. Chye, Y.C. Hseu, S.H. Liang, C.H. Chen, S.C. Chen, Single strand DNA breaks in human lymphocytes exposed to para-phenylenediamine and its derivatives, Bull. Environ. Contam. Toxicol. 80 (2008) 58-62.

[9] L.M. Gonçalves, W.F.A. Callera, M.D.P.T. Sotomayor, P.R. Bueno, Penicillinase-based amperometric biosensor for penicillin G, Electrochem. Commun. 38 (2014) 131-133.

[10] J.J. Gooding, F. Mearns, W. Yang, J. Liu, Self-assembled monolayers into the 21st century: recent advances and applications, Electroanalysis 15 (2003) 81-96.

[11] W.C. Ribeiro, L.M. Gonçalves, S. Liebana, M.I. Pividori, P.R. Bueno, Molecular conductance of double-stranded DNA evaluated by electrochemical capacitance spectroscopy, Nanoscale 8 (2016) 8931-8938.

[12] F.C. dos Santos, L.M. Gonçalves, C.D.S. Riccardi, A.A. Barros, P.R. Bueno, Quartz crystal microbalance as a tool for kinetic enzymatic assays by variation of $\mathrm{pH}$, Anal. Biochem. 418 (2011) 152-154.

[13] M. Trojanowicz, K. Kolacinska, Recent advances in flow injection analysis, Analyst 141 (2016) 2085-2139.

[14] L.M. Gonçalves, J.G. Pacheco, P.J. Magalhães, J.A. Rodrigues, A.A. Barros, Determination of free and total sulfites in wine using an automatic flow injection analysis system with voltammetric detection, Food Addit. Contam. Part A 27 (2010) 175-180.

[15] M. Trojanowicz, Recent developments in electrochemical flow detections-a review: part I. Flow analysis and capillary electrophoresis, Anal. Chim. Acta 653 (2009) 36-58.

[16] B.C. Huayhuas-Chipana, J.C.M. Gomero, M.D.P.T. Sotomayor, Nanostructured screenprinted electrodes modified with self-assembled monolayers for determination of metronidazole in different matrices, J. Braz. Chem. Soc. 25 (2014) 1737-1745.

[17] L. Srisombat, A.C. Jamison, T.R. Lee, Stability: a key issue for self-assembled monolayers on gold as thin-film coatings and nanoparticle protectants, Colloids Surf. A Physicochem. Eng. Asp. 390 (2011) 1-19.

[18] M.D. Maximino, C.S. Martin, F.V. Paulovich, P. Alessio, Layer-by-layer thin film of iron phthalocyanine as a simple and fast sensor for polyphenol determination in tea samples, J. Food Sci. 81 (2016) 2344-2351.

[19] W.d.J.R. Santos, A.L. Sousa, M.d.P.T. Sotomayor, F.S. Damos, S.M.C.N. Tanaka, L.T. Kubota, A.A. Tanaka, Manganese phthalocyanine as a biomimetic electrocatalyst for phenols in the development of an amperometric sensor, J. Braz. Chem. Soc. 20 (2009) 1180-1187.

[20] A. Dedinaite, M. Ernstsson, Chitosan-SDS interactions at a solid-liquid interface: effects of surfactant concentration and ionic strength, J. Phys. Chem. B 107 (2003) 8181-8188.

21] M.X. Chen, B.K. Li, D.K. Yin, J. Liang, S.S. Li, D.Y. Peng, Layer-by-layer assembly of chitosan stabilized multilayered liposomes for paclitaxel delivery, Carbohydr. Polym. 111 (2014) 298-304.

[22] A. Saydjari, J.P. Long, W.J. Dressick, B.S. Simpkins, Optical interference effect corrections for absorbance spectra of layer-by-layer thin films bearing covalently bound dye, Chem. Phys. Lett. 608 (2014) 328-333.

[23] R. Jayakumar, M. Prabaharan, S.V. Nair, H. Tamura, Novel chitin and chitosan nanofibers in biomedical applications, Biotechnol. Adv. 28 (2010) 142-150.

[24] K. Tsourounaki, M.J. Bonné, W. Thielemans, E. Psillakis, M. Helton, A. McKee, F. Marken, Nanofibrillar cellulose-chitosan composite film electrodes: competitive binding of triclosan, Fe(CN)6 3-/4-, and SDS surfactant, Electroanalysis 20 (2008) 2395-2402.

[25] S.T. Dubas, C. Iamsamai, P. Potiyaraj, Optical alcohol sensor based on dye-chitosan polyelectrolyte multilayers, Sensors Actuators B Chem. 113 (2006) 370-375.

[26] M.B. Gholivand, G. Malekzadeh, M. Torkashvand, Enhancement effect of sodium-dodecyl sulfate on the anodic stripping voltammetric signal of phenylephrine hydrochloride at carbon paste electrode, J. Electroanal. Chem. 704 (2013) 50-56.

[27] E. Laborda, A. Molina, F. Martínez-Ortiz, R.G. Compton, Electrode modification using porous layers. Maximising the analytical response by choosing the most suitable voltammetry: differential pulse vs square wave vs linear sweep voltammetry, Electrochim. Acta 73 (2012) 3-9. 
[28] A.M. Carvalho, L.M. Gonçalves, I.M. Valente, J.A. Rodrigues, A.A. Barros, Analysis of cardamonin by square wave voltammetry, Phytochem. Anal. 23 (2012) 396-399.

[29] V. Mirceski, E. Laborda, D. Guziejewski, R.G. Compton, New approach to electrode kinetic measurements in square-wave voltammetry: amplitude-based quasireversible maximum, Anal. Chem. 85 (2013) 5586-5594.

[30] V. Mirceski, R. Gulaboski, M. Lovric, I. Bogeski, R. Kappl, M. Hoth, Square-wave volt ammetry: a review on the recent progress, Electroanalysis 25 (2013) 2411-2422.

[31] P.G. Wang, A.J. Krynitsky, Rapid determination of para-phenylenediamine by gas chromatography-mass spectrometry with selected ion monitoring in henna-containing cosmetic products, J. Chromatogr. B Anal. Technol. Biomed. Life Sci. 879 (2011) 1795-1801

[32] A. Meyer, B. Blömeke, K. Fischer, Determination of $p$-phenylenediamine and its metabolites MAPPD and DAPPD in biological samples using HPLC-DAD and amperometric detection, J. Chromatogr. B Anal. Technol. Biomed. Life Sci. 877 (2009) 1627-1633.

[33] S.-P. Wang, H.-J. Chen, Separation and determination of nitrobenzenes by micellar electrokinetic chromatography and high-performance liquid chromatography, J. Chromatogr. A 979 (2002) 439-446.

[34] K. Ngamdee, S. Martwiset, T. Tuntulani, W. Ngeontae, Selective fluorescence sensors for $p$-phenylenediamine using formyl boronate ester with an assistance of micelles, Sensors Actuators B Chem. 173 (2012) 682-691.

[35] F.F. Hudari, L.C. de Almeida, B.F. da Silva, M.V.B. Zanoni, Voltammetric sensor for simultaneous determination of $p$-phenylenediamine and resorcinol in permanent hair dyeing and tap water by composite carbon nanotubes/chitosan modified electrode, Microchem. J. 116 (2014) 261-268. 